\section{Contributors}

lain Bamforth

iainbamforth@orange.fr

Sarah Cranfield

sarahcranfield@doctors.org.uk

Peter JM Davis

peter.davis@whitnashmc.nhs.uk

Olumide Elegbe

oelegbe@nhs.net

Mark Gabbay

m.b.gabbay@liverpool.ac.uk

Stephen Humphrys

stephen.humphreys@nhs.net

Chris Johnstone

christopher.johnstone@ntlworld.com

Rodney P Jones

hcaf_rod@yahoo.co.uk

Michael Lasserson

mlasserson@hotmail.com

Helen Lester

Helen.Lester@manchester.ac.uk

Ian Mackenzie

macken34@liv.ac.uk

\title{
Princes Gate: in memoriam
}

A sunny day in Summer 1989 - climbing the College stairs slowly, being ushered into the Long Room, and sitting nervously beneath the gaze of past presidents. An examiner in a short-sleeved shirt asked me about the management of hypertension and signs of child neglect. The next examiner suggested a book I might like to read which I duly noted down. After thanking him for the advice, I ran down those stairs and out into the sunshine. It was the beginning of a long and happy relationship with Princes Gate.

I remember my first invitation to a College supper: the gold rimmed card, the 'carriages at 11', the excitement, and pride. I bought a new dress, had my hair done and took a day's annual leave. Now I'm more likely to catch the late afternoon train from New Street, fall through the College front door at 7.30, throw my coat into the cupboard, and pull my skirt straight. But the sense of honour and occasion has never faded. Over the decades, those wood panelled rooms have provided a neutral space, a safe place to test out ideas with policy makers and ministers. The sense of being in someone's home creates an atmosphere of genteel informality where issues of the day are discussed and debated. There's also a real sense of equality of opportunity, with younger members invited to share their views and experiences with College elders and invited guests.

It's a house with a history - with hints of danger and glamour. Joseph Kennedy, JFK's father, lived there as the American ambassador, holding parties in the Long Room for royalty. More recently, I remember the television coverage of the Iranian Embassy siege at 16 Princes Gate. The College was evacuated and the SAS used it as a base to plan their operations, drilling holes in the walls to watch what was going on. On the fifth day, the SAS stormed the building, abseiling from the roof, bursting through a wall, and throwing grenades through the front window of the Embassy. Some taxi drivers may now look blankly when you ask for the RCGP but all nod wisely when you mention the Embassy.

However the building has been struggling to contain College aspirations and activities for some time. We moved in, in January 1963 and have now outgrown our first proper home. Activities and staff are on multiple sites, both in and outside London. Many people are working in cramped attic and basement rooms that you rarely see as a visitor. The chairman's office is a shoe box with room for four if you all breathe in. I've also heard arguments that perhaps we need a 'grander' building to reflect the increased standing of the profession and the College. I'm not certain that's a good reason to move - standing is earned through wisdom and work - but our new home in 2 years time at Euston Square, is certainly imposing and spacious. It too has an interesting former life and architectural history currently hidden beneath layers of cladding and scaffolding, ready to be revealed to us all in Summer 2012 - the 60th anniversary of the College.

Of course the College is not the building. It's the people, staff and members, the culture, the shared history, the plans for the future. But my College experience is inextricably bound up with 14 Princes Gate. I will miss the cheapest bedrooms in London with their genteel shabbiness and creaky floors; the tranquillity of the terrace in the mornings; the roof of the Albert Hall glinting in the sunshine; the library with its cupboard stuffed with theses from our academic forefathers at the start of their careers; sitting on the sofas beneath the gold embossed names of former officers and of the Foundation Council members.

A sunny day in Summer 2010 - the College Council meeting before the doors closed for the last time on the 15th of August. We all trooped out onto the terrace for a final group photo. We laughed and smiled. The Red Arrows flew past. They said it was for the Queen ...

DOI: 10.3399/bjgp10X515629 